\title{
Revisão bibliográfica sobre os efeitos da radiação luminosa de lâmpadas eletrônicas na visão humana
}

\author{
Review on the effects of luminous radiation of electronic lamps on human vision
}

\author{
Alessandro de Albuquerque Silva, Raphael Alves dos Santos, Frederico Novaes da Fraga* \\ Como citar esse artigo. Silva, AA; \\ Da Fraga, FN; Dos Santos, RA. \\ Resumo
}

Revisão bibliográfica sobre os efeitos da radiação luminosa de lâmpadas eletrônicas na visão humana. Revista Teccen. 2020 Jan./Jun.; 13 (1): 33-40.

\begin{abstract}
O campo da iluminação vem sofrendo constantes alterações ao longo dos últimos anos em decorrência das pesquisas e dos avanços das tecnologias envolvidas por ele. Considerando a utilização da iluminação pelo ser humano, existem diversas normas que buscam garantir a qualidade e o conforto do usuário em ambientes que disponham da iluminação proporcionada por esses dispositivos, além de garantir sua saúde, visto que vários dispositivos produtores de iluminação artificial, como smartphones, tablets e afins causam prejuízo à visão humana. Este trabalho consiste num estudo bibliográfico sobre lâmpadas, normas e sobre a luz azul violeta, buscando identificar a presença desse componente danoso nas lâmpadas eletrônicas e se há alguma menção a isso nas normas especializadas. Segundo a pesquisa realizada, os equipamentos eletrônicos emitem a luz azul violeta, prejudicial à visão humana, porém, nas lâmpadas de LED, esse potencial danosos não se detecta, ao menos no estado da questão, e que não existe, também, menção a esses danos na norma. Concluiu-se que se deve seguir a experimentação e ensaios para referendar ou impugnar os resultados da pesquisa bibliográfica.

Palavras-Chave: Lâmpadas; Luminotécnica; Visão; Normas.
\end{abstract}

\begin{abstract}
The lighting field has undergone constant changes over the past few years as a result of research and advances in technologies applied by him. Allow the use of lighting by humans, several standards that the bus will guarantee the quality and comfort of the user in environments that have lighting provided by these devices, in addition to ensuring their health, since several devices produce artificial lighting, such as smartphones, pills and the like cause damage to human vision. This work consists of a bibliographic study about lamps, standards and about blue violet light, seeking to identify the presence of this damaged component in electronic lamps and if there is any mention in these applicable standards. According to research conducted, electronic equipment emitted by violet blue light, harmful to human vision, however, in LED lamps, this potential undetected damage, at least in the state of the matter, and which does not exist, also affects these damages in standard. It was concluded that it should follow an experimentation and essays for reference or challenge the results of the bibliographic research.

Keywords: Lamps; Lighting; Vision; Standards.
\end{abstract}

\section{Introdução}

As lâmpadas estão presentes no cotidiano desde do fim do século XIX, ao menos eu seu arquétipo atual. Com o passar do tempo, as tecnologias que envolvem a iluminação continuam em constante processo de evolução, bem como todas as outras (Fraga, 2020).

No decorrer desse processo, diversas regulamentações surgiram para que os projetos de iluminação pudessem atender o usuário sem causarlhe danos. Nos últimos anos, diversas pesquisas, acompanhando o desenvolvimento dessas novas tecnologias de baixo consumo, como lâmpadas fluorescentes ou LEDs, têm evidenciado o fato de que essas tecnologias podem causar prejuízos ao usuário se não forem utilizadas corretamente.

Esta pesquisa surge a partir da leitura de alguns artigos veiculados na imprensa (Presse, 2019; Faustino, 2018) que atestavam um problema: os danos à visão gerados por diversos eleteônicos devido à exposição excessiva daquela a estes nos dias atuais, principalmente coasionada pela presença cada vez mais idissociável desses equipamentos na rotina dos homens. Este dano é causado pela luz azul violeta, uma cor com alta potência luminosa, emitida por esses aparelhos.

Partindo disso, este trabalho busca apresentar

Afiliação dos autores:

Universidade de Vassouras, Vassouras, Rio de Janeiro, Brasil 
uma revisão de literatura sobre o tema, que consistiu na leitura das normas de luminotécnica pertinentes e no estudo da bibliografia especializada sobre os efeitos da luz azul violeta na visão humana. A partir disso, procurou-se realizar um estudo mais detalhado da norma, para perceber em que pontos ela contemplava os pontos ressaltados pela bibliografia sobre luz azul violeta, e se esta questão é pertinente quando aplicada às lâmpadas fluorescentes e LEDs. Na primeira parte, este trabalho tratará das lâmpadas fluorescentes e LEDs, esclarecendo constituição e funcionamento. $\mathrm{Na}$ segunda parte, falar-se-á um pouco sobre as normas de luminotécnica, suas características e principais pontos. $\mathrm{Na}$ terceira parte, serão explanados alguns conceitos relacionados à natureza da luz e sua influência na visão humana, bem como a natureza da luz azul violeta e os danos que pode causar. Unindo as anteriores, a quarta parte faz uma discussão sobre o assunto, comparando as normas aos apontamentos da bibliografia, possibilitando uma conclusão.

\section{Metodologia}

Este trabalho consiste numa revisão bibliográfica, buscando trabalhos nas bases de dados Google Scholar e Scielo, bem como fontes impressas e outros trabalhos acadêmicos, para nela identificar referências aos malefícios causados pela luz azul violeta na visão humana e se, além de eletrônicos como smarthpones, computadores e afins, as lâmpadas eletrônicas também apresentam esses malefícios.

Mais detalhadamente, este trabalho se iniciará por compor um estado da arte das lâmpadas eletrônicas, LEDs e fluorescentes, conhecidas como econômicas, descrevendo constituição e funcionamento. Será feita, em seguida, uma breve descrição das normas de luminotécnica, bem como uma apresentação de alguns conceitos fundamentais nelas presentes. Segue-se uma breve descrição dos tipos de ondas eletromagnéticas a que o ser humano está submetido, dando maior ateção à radiação luminosa, e à luz azul violeta em especial, fundamental patra este trabalho. Depois, será descrita a pesquisa levada a cabo por Silva, Maia, Pinheiro, Matias, Salvo, André e Forreaux (2015), para identificar o dano causado pela exposição constante a essa radiação, emitida por diversos dispositivos eletrônicos.

Por fim, será feita uma discussão em torno dos resultados obtidos com a pesquisa e serão apresentadas as considerações finais.

\section{Lâmpadas de Baixo Consumo}

Lâmpadas são equipamentos responsáveis por emitir luz, e podem ser de vários tipos. Históricamente, a primeira a ser utilizada foi a de arco elétrico, desenvolvida por Sir Humphry Davy, sendo sucedida pela lâmpada a filamento, desenvolvida por um engenheiro que trabalhava nos laboratórios de Thomas Edison (Fraga, 2020). Esta lâmpada é o modelo para a lâmpada a filamento de tungstênio que dominava o mercato até os princípios da década de 2010. Seu funcionamento se dava pelo aquecimento do filamento supracitado através de corrente elétrica, porém num ambiente hermético, impedindo a combustão do fio e possibilitando, consequentemente, a emissão de luz. No entanto, devido à necessidade de aquecimento, são lâmpadas pouco eficientes, e vieram a ser substituídas pelas fluorescentes.

As lâmpadas fluorescentes são constítuidas de um reator - que pode estar embutído ou não à sua estrutura, a depender da finalidade e da robustez da lâmpada - e de um tubo de vidro com paredes internamente revestidas por pó de fósforo. Seu funcionamento se dá através da excitação elétrica dos gases internos do tupo, que podem ser, em geral, vapor de mercúrio (Hg) ou argônio (Ar), gerando liberação de energia eletromagnética ultravioleta, que extica o pó de fósforo, fanzendo-o emitir luz visível. Elas surgem nas pesquisas de Nikola Tesla sobre alternativas de equipamentos elétrico, principalmente às lâmpadas fabricadas por Edison, sendo postas no mercado por volta da década de 1940, sendo saudadas como uma alternativa às incandescentes, produzindo "uma qualidade de luz que é o mais próximo da luz no dia já alcançado", sendo "muito maior se comparado às lâmpadas incandescentes. (Strand, 1940).

Segundo Ferreira (2014), a eficiência da lampada fluorescente é alta, apresentando tempo de duração entre 7.500 a 10.000 horas.

As Lâmpadas fluorescentes são, no entanto, muito prejudiciais ao meio ambiente, pois seu descarte libera mercúrio, substância que pertence à sua composição e que gera altos danos ambientais, tanto ao solo quanto ao lençol freático. Segundo Wang et al (como citado em Santos, Batista, Pozza e Rossi, 2015, p. 596), "o mercúrio pode afetar todos os grupos de organismos e Ecossistemas, incluindo microrganismos da água e solo e a fauna de uma maneira geral". Diversos prejuízos à saúde humana quando exposta à mercúrio são relatados na literatura, o que inclui casos de Alzheimer e Parkinson, além de proporcionar aumento da mortalidade infantil (Santos et al, 2015). Com o avanço da tecnologia e o aprimoramento da mesma, propondo abordagens mais eficientes e sustentáveis, e até por causa da educação humana por parte de descartes das lâmpadas ao meio ambiente para que não venham a ocorrer mais, então, o consumo de lâmpadas LED está sendo introduzido e influenciado através de campanhas de divulgação e da legislação (Santos, 2016).

As Lâmpadas de LEDs (Light Emitting Diode), são dispositivos semicondutores que são revestidos 
com alguns tipos de gases, e diferentes materiais como fósforo $(\mathrm{P})$, sendo um importante componente para a geração da luz os chips de minúscula dimensão, a emissão da luz recebe o nome de eletroluminescência. $\mathrm{O}$ LED é composto por condutores de cristais de silício e que são encapsulados por uma resina epóxi transparente semicondutor (Santos, 2016). A composição para as descobertas dos LEDs coloridos foi a parti de 1963, em que se descobriu experimentalmente pela cor vermelha que tinha baixa claridade. Na década 1975 foi introduzido uma das descobertas da cor verde, e após 20 anos depois foi descoberto a luz branca. E com o avanço das tecnologias veio aprimorando melhor a eficiência dos LEDs nos dias atuais. Segundo LPR (conforme citado em Santos et al, 2015):

No início dos anos 1990, houve a principal revolução do LED e a possibilidade de aplicá lo no setor automotivo, por exemplo. Após obter se LEDs com comprimento de ondas menores, nas cores azul, verde e ciano, tecnologia esta que propiciou a obtenção do LED branco, e consequentemente, todos os espectros de cores (Santos et al, 2015, p.597).

As lâmpadas LED vêm ganhando espaço no mercado, principalmente por sua duração e qualidade de sua tecnologia.

Segundo Ferreira (conforme citado em Santos, 2016), os LEDs possuem baixo consumo, vida útil extremamente longa e estão casa vez mais eficientes. Os LEDs são monocromáticos, emitem luz somente numa faixa do espectro da luz, apresenta uma vida útil de 100.000 horas. As lâmpadas de LEDs são atóxicas, ou seja, não trás malefícios para o meio ambiente, prejudicando o solo, podendo ser descartados sem procedimentos especiais de segurança (Santos et al, 2015).

\section{Normas Referentes à Luminotécnica}

A luminotécnica trata de um conjunto de conhecimentos e métodos aplicados ao desenvolvimento de um ambiente luminosamente confortável para o usuário. $\mathrm{O}$ método dos lumens, o método ponto aponto,bem como o uso de softwares próprios para o cálculo, tais como DIALux e CALCULUX, são alguns dos intrumentos disponíveis para tal realização (Creder e Costa, 2018).

Todas essas ferramentas são regidas pelas normas de luminotécnica, que abordam conceitos que dão base aos métodos. Dentro do campo das engenharias, para facilitar e regulamentar as atividades, existem associações e normas, tanto nacionais quanto internacionais. No caso brasileiro, a entidade responsável por elaboração, edição e emissão de normas técnicas é a Associação Brasileira de Normas Técnicas (ABNT), que emite suas resoluções através das NBRs, que são as normas regulamenetadoras das atividades. Dentro das diversas resoluções, as de interesse da luminotécnica são as NBRs 5413/1992, 5461/1991 e 5482/1985.

A NBR 5413/1992 trata das regras referentes ao cálculo de iluminação artificial para para diversas atividades: comercio, ensino, esportes entre outros. Ela está ancorada em duas outras normas, NBR 5382/1985 e NBR 5461/1991.ANBR 5382/1985 fornece parâmetros e métodos para verificar a iluminância de partes interiores. A NBR 5461 fornece a terminologia utilizada no cálculo de luminotécnica, abrangendo diversos conceitos, tais como radiação, visão, calorimetria, emissão, medições radiométricas, fotométricas e calorimétricas, efeitos actínicos da radiação óptica, fontes de luz, luminárias e seus componentes e sinalização visual (ABNT, 1992).

Essas normas foram posteriormente atualizadas na NBR ISO/CIE 8995-1, de 2013 - e, por conseguinte, canceladas. Essas alterações foram devido a pontos não contidos nas anteriores ou pouco desenvolvidos, tais como (ABNT, 2013):

- Ambiente luminoso, que deve proporcionar conforto para locais de trabalho, objetivando melhorar a visualização. $\mathrm{O}$ ambiente luminoso deve possuir algumas caracteristicas: conforto visual, melhorando a sensação para os trabalhadores; desempenho visual, ficando melhor a visualização dos trabalhadores; segurança visual, descobrir perigos ao seu redor. Tem também de satisfazer outros parâmetros, que são: distribuição da luminância, iluminância, ofuscasmento, direcionalidade da luz, aspectos da cor da luz e superfícies, cintilação, luz natural, manutenção;

- Distribuição da iluminância, que, quando bem feita, proporciona uma melhor adaptação dos olhos ao ambiente, e não afeta a visibilidade nas tarefas. Ou seja, para uma adaptação melhor e " balanceada";

- Iluminância, serve para áreas de distribuição de trabalho e traz melhoria para pessoas fisicas ao realizar tarefa visual com rápidez, segurança e conforto. Os valores de iluminância determinados na norma trazem uma segurança visual no trabalho e alguns outras funções no desempenho visual;

- Uniformidade, diz que a razão da iluminância tem que ser entre o valor mínimo e valor médio. A uniformidade da iluminância de tarefa não pode ser menor que 0,7 , mas a uniformidade entorno no entorno imediato não pode ser inferior 0,5 ;

- Ofuscamento, que é produzido por áreas brilhantes dentro do campo de visão, tornando-se desconfortável, chegando a ser inibidor. O ofuscamento também é causado por reflexões de superfícies especulares ou ofuscamentos refletidos. É importante 
evitar o ofuscamento para evitar erros dos usuários entre fadigas e acidentes;

- Aspectos de cor, lâmpadas próximas a cor branca possuem qualidade e carateristicas devido a dois atributos: a aparência de cor própria lâmpada, sua capacidade de reprodução de cor, que afeta a aparência da cor de objetos e das pessoas iluminadas pela lâmpada. Os dois atributos devem ser levados em conta separadamente;

- Iluminação de estações de trabalho com monitores VDT (Visual display terminals (também conhecido como monitores de vídeo e displays visuais), iluminação extra para algumas áreas dedicadas a tarefas determinadas: leitura de telas, escritas no papel, etc. Em algumas situações o uso do monitor VTD, ou teclados, pode haver reflexos, ofuscamentos desconfortável. O projetista deverá de analizar esta zona de monategem crítica e escolher um equipamento adequado de iliminância para que não haja reflexos que causem pertubações;

- Cintilação e efeito estroboscópico, a cintilação é danosa aos usuários, pois provoca efeitos fisiológicos, como dor de cabeça. Convém que seja instalado um sistema iluminação para que não ocorra malefício, e evitar a cintilação e os efeitos estroboscópicos. Os efeitos estroboscópicos pode levar o usuário a mudança de percepção de movimentos de rotação, ou seja, perigo.

\section{Luz Azul Violeta e seus Efeitos na Visão Humana}

Os conceitos fundamentais que essa norma abrange são relativos às radiações luminosas. As radiações comportam-se, segundo a teoria quântica, ora como ondas, ora como partículas. Seu comportamento ondulatório é a parte interessante para a norma, onde as definições dadas irão se encaixar. Para definir a radiação luminosa como uma onda, são necessários dois conceitos básicos, comprimento de onda e frequência.

$\mathrm{O}$ que se entende por luz é uma determinada família de ondas eletromagnéticas que podem ser detectadas pelo olho humano. A distribuição dessas ondas se dá em função da ração entre sua velocidade (V) e sua frequência (f), estabelecendo-se uma medida chamada comprimento de onda (eq. 1), dada em nanômetros, nm, extraída da equação de Herz para as ondas eletromagnéticas (eq. 2) (Halliday, Resnick e Walker, 2009; Tipler e Mosca, 2009).

$$
\begin{array}{ll}
\lambda=V / f & \text { Eq. } 1 \\
V=\lambda f & \text { Eq. } 2
\end{array}
$$

A Figura 1 ilustra a distribuição dos comprimentos de onda, podendo-se notar, inclusive, que o espectro visível é muito diminuto em relação à totalidade do espectro conhecido. Em uma onda senoidal, o comprimento de onda "é a distância (paralela à direção de propagação da onda) entre repetições da forma de onda". Pode, então, ser representada pela distância entre picos (máximos), vales (mínimos), ou duas vezes a distância entre nós.

O comprimento de onda $\lambda$ tem uma relação inversa com a frequência $f$, a velocidade de repetição de qualquer fenômeno periódico. O comprimento de onda é igual à velocidade da onda dividida pela frequência da onda. Quando se lida com radiação electromagnética no vácuo, essa velocidade é igual à velocidade da luz 'c', para sinais (ondas) no ar, essa velocidade é a velocidade

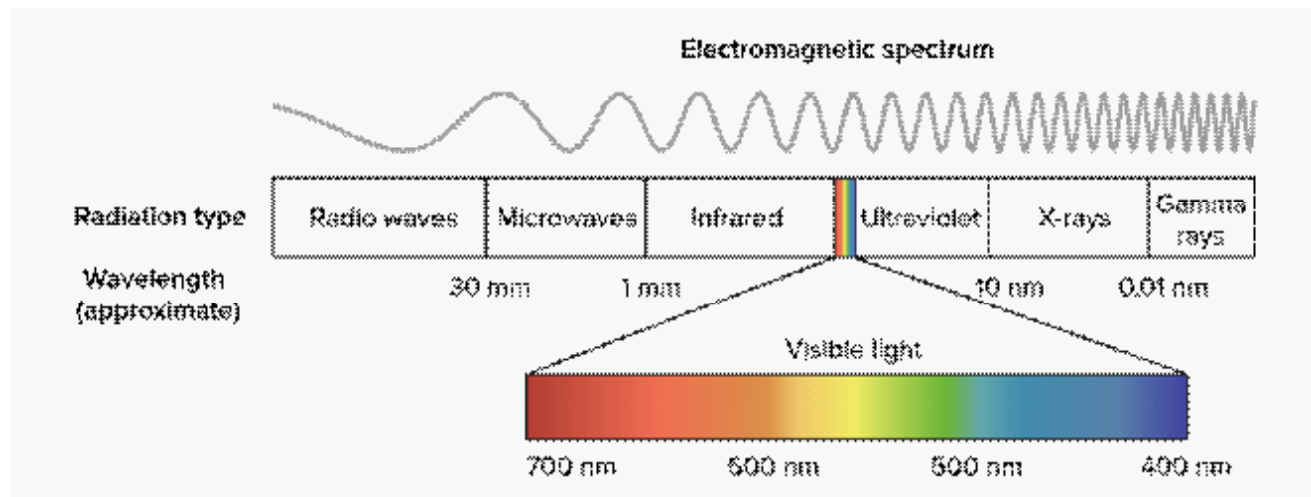

Figura 1. Distribuição dos Comprimentos de Onda. 
na qual a onda viaja (Tipler e Mosca, 2009).

A radiação visível são espectros eletromagnéticos onde que os humanos podem enxergar faixa de cores (vermelho ao violeta, passando pelo verde, o amarelo e o azul), pois a radiação é composta de fotons em que o olho humano é capaz de identificar as cores ao seu redor. A radiação neste caso é como feito pela luz visível.

A radiação invisível são espectros eletromagnéticos que não é possível para que o olho humano consiga ver no seu dia a dia. E para que o olho humano consiga enxergar esses tipos de cores só através da tecnologia, em que o aparelho detecta terminações nervosas da pele em forma de calor, sendo essas radiações ou infravermelhas ou ultravioletas, as radiações UV (Halliday et al, 2009).

Dentre as diversas cores do espectro visível, a que mais interessa aqui é a azul violeta, cujo comprimento de onda dá-se dentre 415 e 455 nm, dada na intersecção do violeta $(\lambda=400-440 \mathrm{~nm})$ com o azul $(\lambda=440-500$ $\mathrm{nm})$, por ser uma cor de alta potência luminosa. O olho humano possui uma proteção natural para luzes intensas como as ultravioletas: a córnea o proteje de raios UV abaixo de $300 \mathrm{~nm}$, e a lente contra os dentre 300 e $400 \mathrm{~nm}$. Porém, como o olho humano deve permitir a passagem de todas as radiações do espectro visível, não existe qualquer proteção na fisiologia do olho para a luz azul violeta, que mesmo muito intensa, é permeável aos meios diópticos.

A radiação da luz azul é extremamente maléfica dada sua presença no cotidiano. Os sintomas de danos à visão são percebtíveis quando há períodos de intensa exposição à essa radiação, porém, com o uso prolongado e constante, os danos são menos sensíveis, pois os efeitos maléficos se dão paultaninamente. A exposição prolongada a essa radiação acarreta degeneração da visão, conhecida como DMRI, degeneração macular relacionada à idade. Para os humanos que ficam expostos prolongadamente à luz azul, ainda mais no período noturno, ocorre afetação no ritmo circadiano, causando vários efetios nocivos. A luz azul, por afetar a retina, afeta a produção de melatonina, substância que promove o sono, e acaba causando desconforto e insônia (Silva et al, 2015).

A radiação das luzes amarela e vermelha não é tão prejudicial quanto luz azul. A luz amarela, como a luz vermalha, possui comprimento de onda mais longo, e não afeta tanto a retina. Elas acabam por não impedir a produção de melatonina, trazendo conforto para o usuário naquele ambiente e a escuridão promove a sensação de sonolência (Legnaiolli, 201-).

Para investigar o potencial danoso dessa radiação, Silva et al (2015) emrpeenderam uma pesquisa de campo com 100 estudantes de 18 a 33 anos. Sua pesquisa consistiu num questionário com diversos pontos:

Da primeira à quarta, os participantes responderam se possuíam computador, smartphone, tablet e outros equipamentos eletrônicos; na quinta pergunta, os participantes responderam se possuíam o hábito de usar o telefone celular em ambiente totalmente escuro, sem nenhuma luminosidade; na sexta e sétima perguntas, eles responderam questões referentes à frequência de utilização de um número de vezes por dia e tempo aproximado; na oitava e na nona perguntas, os universitários responderam questões sobre a existência de problemas de visão e alguns outros sintomas, tais como hiperemia ocular dores de cabeça tontura e visão turva. O preenchimento do questionário bem como os resultados foram tratados de forma anônima (Silva et al, 2015, p. 49).

Os resultados obtidos nessa pesquisa são mostrados nos gráficos representados nas Figuras de número 2 a 6.

Os dados estatísticos coletados permitiram detectar que:

os estudantes universitários possuem um ou mais equipamentos eletrônicos, tais como: smartphones, computadores, tablets e outros. Mais da metade dos universitários utilizam estes equipamentos eletrônicos com uma frequência superior a 8 horas por dia. Além disso, nossos resultados demonstraram que quanto maios a frequência de uso destes equipamentos, maior a incidência de miopia, dores de cabeça e visão turva (Silva et al, 2015, p. 53).

Foi constatado que, como esperado, dadas as configurações atuais da sociedade, esses equipamentos eletrônicos são presença constante no cotidiano, não só dos estudantes, mas da maioria das pessoas. Continuam Silva et al (2015):

estes números refletem o fato dos dispositivos digitais envoverem todos os aspectos da vida moderna, É possível perceber, com grande frequência, que as pessoas utilizam dispositivos eletrônicos desde o momento em que se levantam até o momento em que vão dormir, incluindo o período de tempo em que estão se alimentando, exercitando ou lendo. No entanto, este uso excessivo de dispositivos que emitem luz azul violeta podem danificar as células da retina, e consequentemente, podem causar perda de visão. Ao orrelacionarmos a frequência de uso diário dos equipamentos eletrônicos com problemas de visão, encontramos uma correlação positiva para a miopia, indicando que quanto maior a frequência de uso dos equipamentos eletrônicos, maior a incidência de miopia (Silva et al, 2015, p. 53).

permitindo-os concluir que: "nossos resultados indicam que a ampla utilização de dispositivos digitais, e consequentemente, a excessiva exposição de olho à luz violeta podem estar correlacionados com a miopia, dores de cabeça e visão turva" (Silva et al, 2015, p. 54).

Os dados apresentados nas Figuras $3 \mathrm{~b}$ e 5, destacadamente, identificam a relação entre o uso de celulares e a ocorrência de doenças oftalmológicas. A correlação apresentada foi $\mathrm{P}=0,034$, ou seja, os dados são significativos para fundamentar a conclusão. Em complemento, a correlação entre os sintomas Dor de Cabeça, Hipermia Ocular e Tontura e a frequência de 
A)

Possui Smartphone

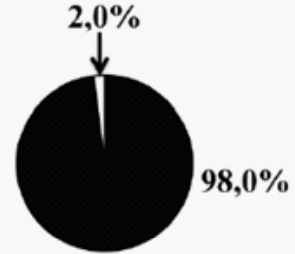

C)

Possui Tablets

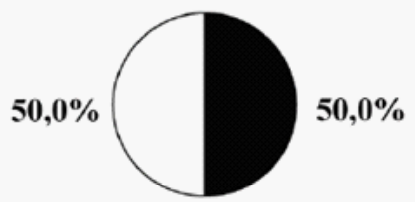

B)

Possui Computador

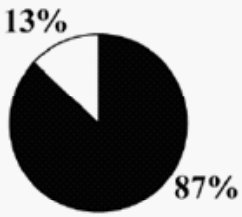

D)

Possui outros equipamentos eletrônicos

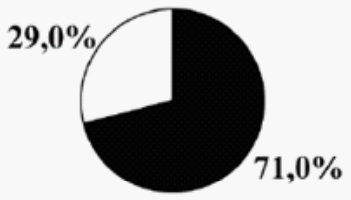

Sim $\square$ Não

Figura 2. Equipamentos Eletrônicos utilizados pelo grupo pesquisado.

Fonte: Silva et al, 2015.

A)

Acesso do celular $\left(n^{\circ}\right.$ de vezes/dia)

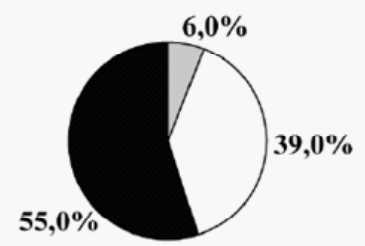

$\square$ 10-20 vezes $p / d i a$

$\square$ 20-30 vezes $p /$ dia

Mais de 30 vezes $p /$ dia
B)

Frequência (em horas) de uso do celular

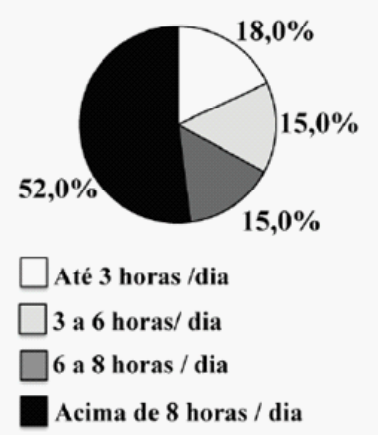

Figura 3. Frequência de uso de celulares em números de acesso por dia. Fonte: Silva et al, 2015

\section{Uso do celular em ambientes escuros}

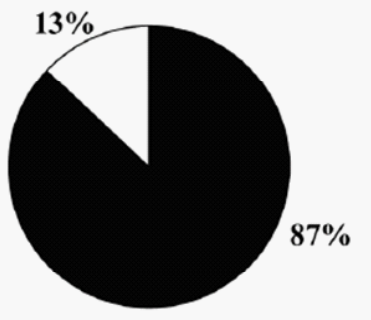

Sim $\square$ Não

Figura 4. Uso habitual de celulares em ambientes totalmente escuros, sem nenhuma luminosidade.números de acesso por dia. 


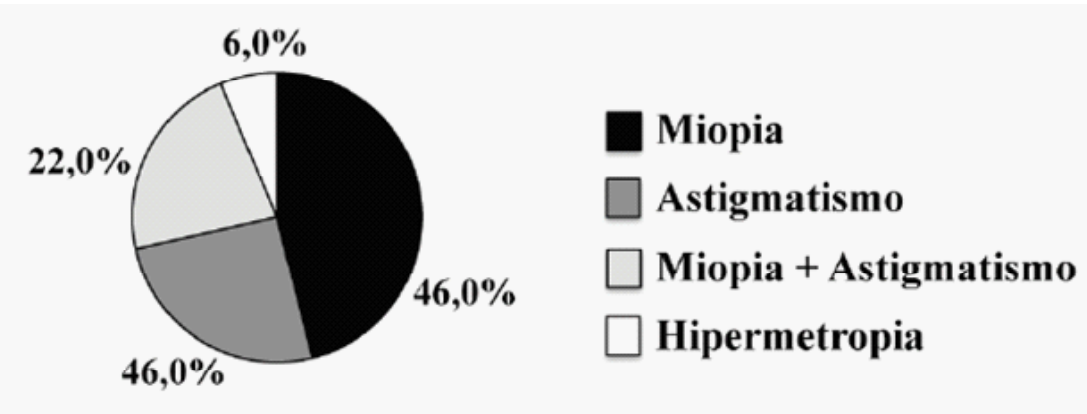

Figura 5. Prevalência de problemas de visão na população estudada.

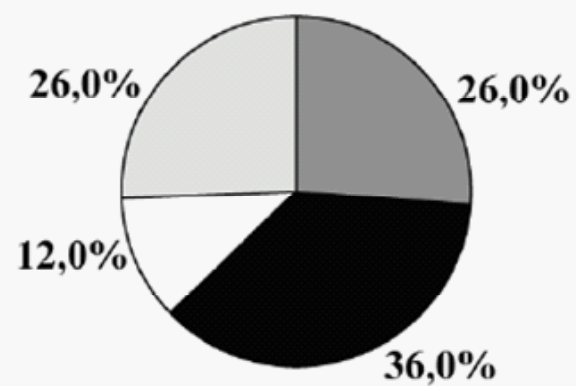

Dores de cabeça

$\square$ Hipermia ocular

$\square$ Visão turva

$\square$ Tontura

Figura 6. Prevalência de desconfortos oculares decorrentes do uso excessivo de dispositivos digitais.

Fonte: Silva et al, 2015.

uso (Figura $3 \mathrm{~b}$ ) foi de $\mathrm{P}=0,043$, ainda representativo, e ela e Visão Turva de $\mathrm{P}=0,031$. Os autores não disponibilizam os dados brutos para conferência.

Existem alguns filtros capazes de reduzir o prejuízo proporcionado pela radiação - não são uma teconogia totalmente eficaz, fazendo com que os cientistas continuem a trabalhar em tecnologias novas.

Soares (2018) conclui:

Segundo Ana Paula Tupynambá, oftalmologista do centro Visão Institutos Oftalmológicos, em Brasília, explica que a pesquisa espanhola trata de um problema bastante conhecido na área médica. "Todo o excesso de luz azul pode causar algum dano à retina, principalmente de aparelhos eletrônicos, como smartphones. A preocupação é tanta que temos empresas criando esses telefones inteligentes com um filtro amarelo para evitar essa exposição", conta (Soares, 2018).

\section{Discussão}

A pesquisa por bibliografia resultou em literatura especializada emlâmpadas, como Ferreira(2014), Santos (2016), Santos et al(2015) e Pessoa e Ghisi (2014), nas normas ABNT NBR 5413 (ABNT, 1992) e ANBT NBR
ISO/CIE 8995-1 (ABNT, 2013), e na pesquisa de Silva et al (2015). Partindo desse materia, foram compostas as três seções anteriores deste trabalho.

Retomando o propósito inicial: pretendia-se compor uma base teórica sobre lâmpadas e radiação luminosa em que se pudesse observar o problema da influência negativa da luz azul violeta sobre a visão humana. Partindo das reportagens citadas na introdução, seguiu-se à perquisa, visando compreender melhor o problema e, se possível, estendê-lo a outras searas, diga-se: lâmpadas de LED. Considerando a presença dessa radiação danosa em smartphones, tablets e afins, a pergunta norteadora destre trabalho surge: teriam essas lâmpadas, bem como as fluorescentes, algum efeito danoso ao ser humano, por serem também eletrônicas?

A pesquisa veio a confirmar o dano ocasionado pela luz azul violeta à visão, principalmente devido à exposição constante, porém, na literatura reunida, não há menção à presença dessa radiação nas lâmpadas de LED, tampouco nas fluorescentes. Nas normas de luminotécnica, também não há menção a tal presença. Pessoa e Ghisi (2014) encerram seu trabalho afirmando que, dentro da literatura especializada, não há indicações da periculosidade dessas lâmpadas. Esta pesquisa partiu 
daí para referendar ou impugnar essa informação, e acabou por confirmá-la. Tanto que uma das metas aqui pretendidas inicialmente era fazer uma leitura atenta da norma e, com base nas informações colhidas sobre a presença da luz azul violeta nas lâmpadas de LED, propor acréscimos — sendo abandonado após a conclusão do estudo.

Para uma nova consideração desse problema, deve-se partir para ensaiar as lâmpadas, pois a literatura, em seu estado atual, não descreve o problema: por ele não existir, ou por ser uma vereda não explorada, só uma abordagem experimental poderá dizer.

\section{Considerações Finais}

O principal objetivo deste trabalho foi elencar referências para nelas verificar se há alguma relação entre as lâmpadas de LED e a emissão de luz azul violeta, e se essa relação é contemplada pela norma. Diversos trabalhos que apresentam constituição e funcionamento das das lâmpadas, bem como seus tipos, foram reunidos, o que permitiu a reunião de diversos conceitos fundamentais. Também foi possível conhecer a abrangência das normas, e os conceitos fundamentais que ela abarca e ressalta.

No entanto, dentro da base de dados, não foram encontrados muitos artigos que relacionem o tema às lâmpadas, e como anteriormente referido por Pessoa e Ghisi (2014), essa relação é inexistente, pelo menos no que se sabe até a realização destre trabalho. A luz azul é um tema importante, principalmente no apogeu dos eletrônicos vivido nos dias atuais, porém a luminação ambiente parece não figurar dentre os elementos danosos.

A partir dos dados coletados, o que se sugere é, já determinada uma base conceitual para entender o fenômeno, partir para experimentos e ensaios para balizar ou não os resultados deste pequisa bibliográfica. Apenas com os ensaios das lâmpadas será possivel reiterar essas conclusões ou, então, impugná-las.

\section{Referências}

ABNT NBR 5413, de 30 de Abril de 1992. Iluminância de interiores. São Paulo: Associação Brasileira de Normas Técnicas. Disponível em: http:// ftp.demec.ufpr.br/disciplinas/TM802/NBR5413.pdf. Acesso em 21 de março de 2020 .

ABNT NBR ISO/CIE 8995-1, de 21 de Março de 2013. Iluminação de ambientes de trabalho parte 1: Interior. São Paulo: Associação Brasileira de Normas Técnicas. Disponível em: http://paginapessoal.utfpr.edu.br/vilmair/ instalacoes-prediais-1/normas-e-tabelas-de-dimensionamento/NBRISO CIE8995-1.pdf/view.

Creder, Hélio; Costa, Luiz Sebastião. (2018). Instalações Elétricas. Rio de Janeiro: LTC.

Faustino, Rafael. (2018, Agosto 10). Luz azul dos celulares e computadores pode levar à cegueira. Época Negócios. Recuperado de: https:// epocanegocios.globo.com/Tecnologia/noticia/2018/08/luz-azul-dos- celulares-e-computadores-pode-levar-cegueira.html.

Ferreira, Juliana Zandona. (2014). Estudo Comparativo entre Lâmpadas Fluorescentes Tubulares T8 e Tubulares de LED. (Monografia de Espacialização). Universidade Federal do Paraná, Curitiba, Paraná, Brasil.

Fraga, Frederico Novaes da. (2020). Resumo do Documentário Choque e Pavor: Uma História da Eletricidade. Recuperado de: https://medium.com/@ fredericoyfraga/resumo-do-document $\% \mathrm{C} 3 \% \mathrm{~A} 1$ rio-choque-e-pavor-umahist $\%$ C3\%B3ria-da-eletricidade-6a02bff507e6

Halliday, David; Resnick, Robert; Walker, Jearl. (2009). Física. Fundamentos da Física, Volume 4: Óptica e Física Moderna. São Paulo: LTC.

KHAN ACADEMY. (201-). Luz e pigmentos fotossintéticos. Recuperado de: https://pt.khanacademy.org/science/biology/photosynthesis-in-plants/ the-light-dependent-reactions-of-photosynthesis/a/light-and-photosyntheticpigments.

Legnaiolli, Stella. (201-) Luz Azul, o que é, benefícios, danos e como lidar. Recuperado de: https://www.ecycle.com.br/6663-luz-azul.html.

Pessoa, João Lourenço Novaes; GHISI, Enedir. (2014). Relatório Técnico: Eficiência Luminosa de Produtos LED Encontrados no Mercado Brasileiro. Florianópolis: $\mathrm{CB} 3 \mathrm{e}$.

Tipler, Paul; MOSCA, Gene. (2009). Física para Cientistas e Engenheiros, volume 2: Eletricidade e Magnetismo. Rio de Janeiro: LTC.

Santos, Raphael Alves dos. (2016). O Descarte Consciente e Correto de Lâmpadas Fluorescentes para um Meio Ambiente Sustentável. (Dissertação de Mestrado). Universidade de Vassouras, Vassouras, Rio de Janeiro, Brasil.

Santos, Taila Simões dos; Batista, Marília Carone Batista; POZZA, Simone Andréa; ROSSI, Luciana Savoi. (2015). Análise da Eficiência Energética, Ambiental e Econômica entre Lâmpadas LED e Convencionais. Engenharia Sanitária e Ambiental. 20 (4), 595-602.

Silva, Ludimila Caroline; Maia, Letícia Danielly; Prinheiro, Deborah Renata; Matias, Laís da Silva Machado; Salvo, Vinícius Fernandes; André, Jacqueline de Oliveira; Forreaux, Giselle. (2015). Correlação entre a exposição diária à luz azul violeta emitida por dispositivos digitais e a visão dos jovens. Saúde em Revista, 15 (41), 47-55

Soares, Vilhena. (2018, março 23). Tecnologia protege os olhos dos danos causados pela luz do celular. Correio Braziliense. Recuperado de: https:// www.correiobraziliense.com.br/app/noticia/ciencia-e-saude/2018/03/26/ interna ciencia saude, 668610/tecnologia-protege-os-olhos-dos-danoscausados-pela-luz-do-celular.shtml.

Strand, Harold. (1940). Pointers on Installing the New Fluorescent Lamps. Popular Science. 136 (1), 136-141. Recuperado de: https://books.google. com.br/books?id=1iYDAAAAMBAJ\&pg=PA136\&dq=popular+science + January $+1940 \& \mathrm{hl}=$ en $\&$ ei $=\mathrm{cG}$ GMTO34FIKengfuvrXICw\&sa $=$ X\&oi=boo $\mathrm{k} \_$result\&ct $=$result\&redir_esc $=\mathrm{y} \# \mathrm{v}=$ onepage $\& \mathrm{q} \& \mathrm{f}=$ true.

Presse, France. (2019, abril 15). Luzes de LED afetam retina e qualidade do sono alerta governo da França. G1, ciência e saúde. Recuperado de: $<$ https://g1.globo.com/ciencia-e-saude/viva-voce/noticia/2019/05/15/luzesde-led-afetam-retina-e-qualidade-do-sono-alerta-governo-da-franca.ghtml $>$. Acesso em: $18 \mathrm{dez} .2019$ 